\title{
A Study on the Development Model of Tibet's Eco-industry
}

\author{
Wenfeng YANG ${ }^{1, a}$ TingmengShi ${ }^{2, b}$ \\ ${ }^{1,2}$ Agricultural and Animal Husbandry College of Tibet University, Nyingchi 860000, China \\ aTbyang9993@126.com835483525@qq.com, ${ }^{\text {b } 835483525 @ q q . c o m ~}$
}

Keywords: Eco-industry, Eco-environment, Constraints, Development mode

\begin{abstract}
With the dramatic economic development in Tibet, the carrying capacity of natural resources and eco-environment becomes the main factor restricting economic growth. Development of eco-industry is one of the effective ways to achieve coordinated and sustainable development of industrial economy and eco-environment. On the basis of industrial analysis, eco-industry and labor productivity comparison, and eco-environment coordination analysis, this article performs studies on the factors that affect the development of eco-industry in Tibet, including fragile eco-environment, unsound infrastructure, backward ecological economy and technology, and low level of economic development. Finally, this article puts forth three economic development models for the eco-industry with Tibet characteristics: eco-agriculture with plateau characteristics; industrial symbiosis in eco-industrial park; community participation-based ecotourism.
\end{abstract}

\section{Introduction}

Based on the carrying capacity of ecosystem, eco-industry, a network-based and evolution-based industry with efficient economic activities and coordinated ecological functions, follows principles and knowledge of ecological economics [1]. Eco-industry reflects the ecological and economic sustainability. By developing sustainable eco-industrial economy and implementing the coordinated eco-industrial development model closely linked with eco-environment construction and socio-economic environment, we can make industrial development mesh with environmental protection $^{[2]}$.

Tibet's eco-industrial development is relatively backward, and in the context of today's ecological civilization construction, Tibet's eco-industry is facing the changes in developmental pattern, as well as the problems of fitting in with ecological civilization construction, so achieving coordinated and sustainable development of eco-industry and environment is of great importance to Tibet's economic boom. This article explores the new model for Tibet's eco-industry, which can help to promote the optimization and upgrading of Tibet's eco-industry, and provide great theoretical and practical value to Tibet's eco-industrial development and economic construction.

\section{Level and trends of Tibet's industrial development}

\subsection{Level of industrial development}

Tibet is west of the Central China plain, and regarded as part of Western China. It is the traditional homeland of the Tibetan people as well as some other ethnic groups. Tibet takes the road of developing some industries with Tibetan features such as plateau tourism, plateau biological industry, Tibetan medicine, plateau green food, livestock product and farm product processing, ethnic handicrafts, mining and building materials. As of 2014, Tibet's GDP reached 92.083 billion yuan, an increase of $0.3 \%$ over the previous year. From 2006 to 2014, the average annual growth rate of GDP was $9.21 \%$, and the output value of primary, secondary and tertiary industries increased by $3.83 \%, 15.1 \%$ and $11.9 \%$, respectively (Fig. 1 ). 

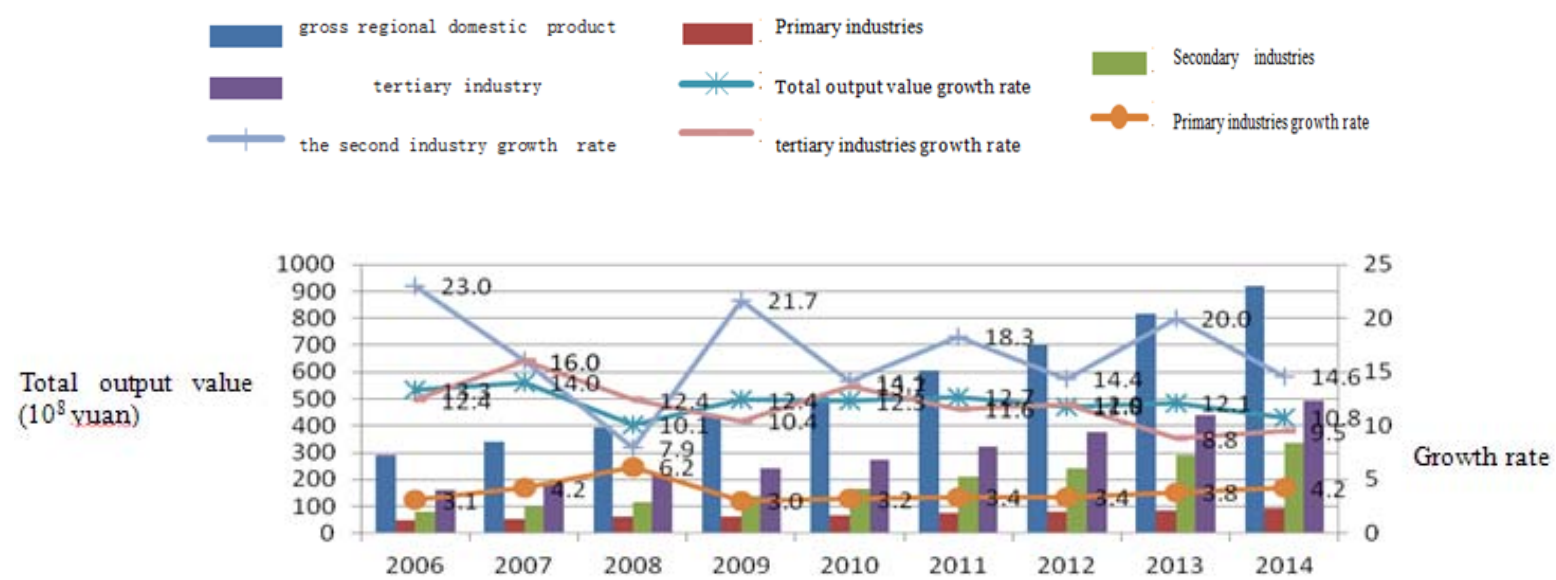

Fig. 1 The changes in output value of industries and its growth rate in Tibet

\subsection{Trends of industrial development}

\subsubsection{Changes in output value of farming, forestry, animal husbandry and fishery}

In 2014, the total output value of farming, forestry, animal husbandry and fishery reached 13.87236 billion yuan, up $7.7 \%$ from that in 2013 . And the output value of farming, forestry, animal husbandry and fishery was 6.32559 billion yuan, 0.26371 billion yuan, 6.93368 billion yuan and 0.01676 billion yuan, respectively. The output value of farming presented a growth of $1.3 \%$ over the previous year; the output value of animal husbandry basically remained unchanged; the output value of forestry and fishery fell by $2.7 \%$ and $21.2 \%$ over the previous year. Tibet's total output value of farming, forestry, animal husbandry and fishery increased from 7.04765 billion yuan in 2006 to 13.87236 billion yuan in 2014 , an average annual growth of $7.6 \%$ (Fig. 2). The sown area of beans, potatoes and forage crops decreased while the sown area of other crops went through different degrees of growth.

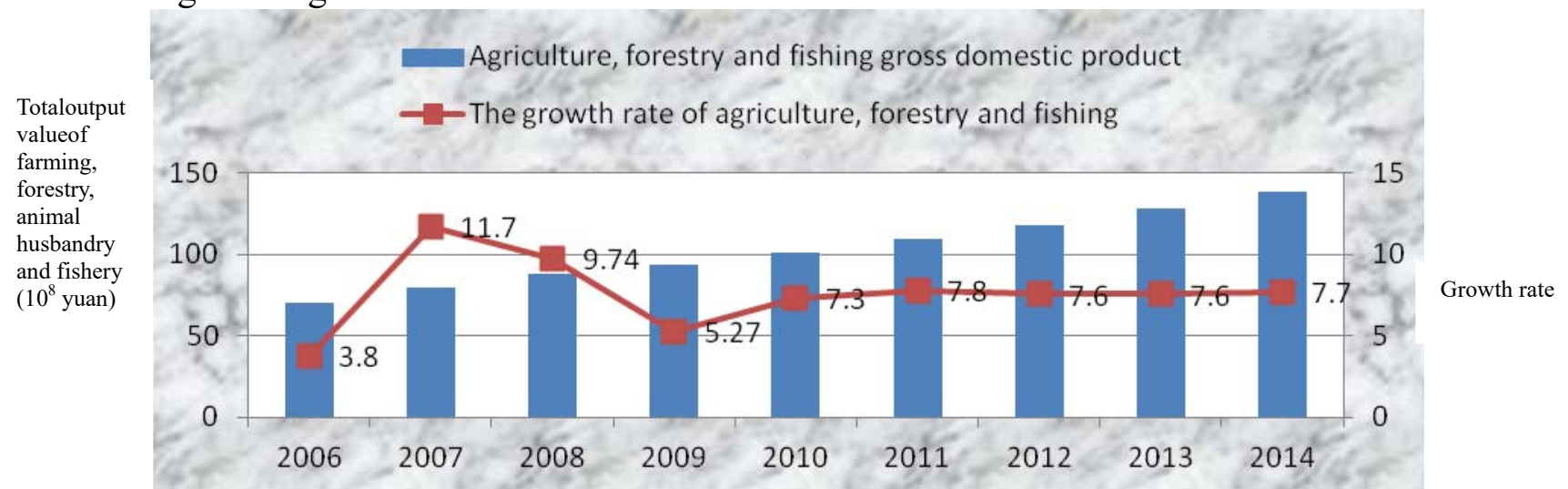

Fig. 2 Annual total output value of farming, forestry, animal husbandry and fishery and its

\subsubsection{Changes in output value of industry} growth rate in Tibet

Tibet's output value of industry increased from 4.01641 billion yuan in 2006 to 15.16709 billion yuan in 2014, an average annual growth of $15.2 \%$ (Fig. 3). A modern industrial system has initially taken shape, and the modern industry with Tibetan characteristics is fast-growing. The modern industrial system is dominated by mining, building materials, ethnic handicrafts, livestock product and farm product processing, plateau green food and hydroelectric energy with Tibetan characteristics. Large-scale enterprises and distinctive industries have become the main channels to promote employment, increase income of farmers and herdsmen, and drive economic development. 


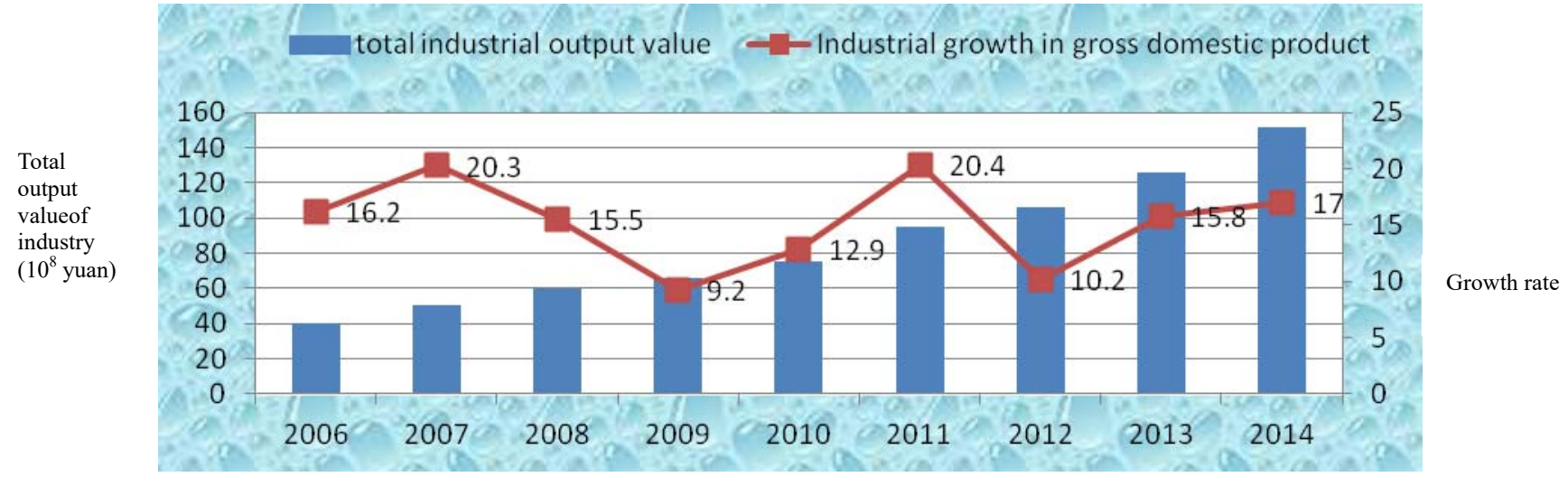

Fig. 3 The annual output value of industry and its growth rate in Tibet

\subsubsection{Dramatic development of tourism}

Tibet's tourism, information industry, transportation, logistics and other tertiary industries show a rapid growth trend, and create economies of scale. In particular, tourism takes the lead to accelerate the development of tertiary industry. About 25.12103 billion tourists at home and abroad visited various tourist spots, and total tourism income reached 2.77072 billion yuan in 2006, and the number of tourists and total tourism income climbed to 15.531413 billion and 20.39989 billion yuan in 2014, respectively (Fig. 4). Both the number of tourists and tourism income continue to increase.

Total number of tourists $\left(10^{4}\right)$
Fig. 4 Change in the number of tourists and tourism income

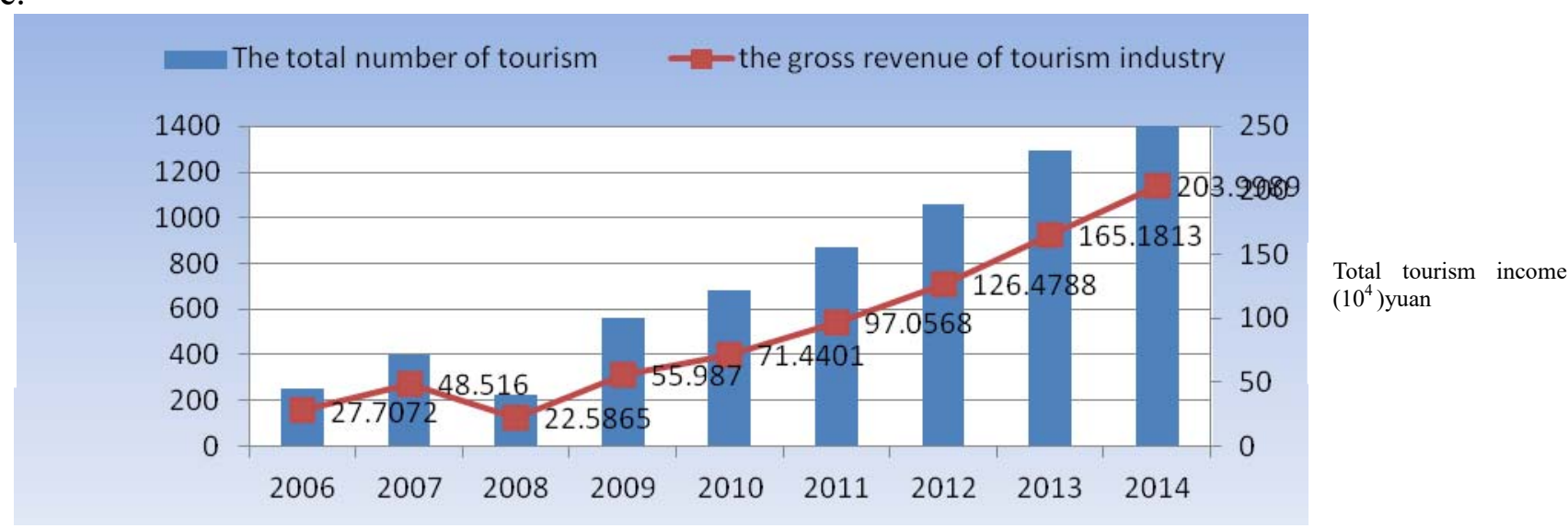

\subsection{Comparative labor productivity}

In 2014, the comparative labor productivity of Tibet's primary, secondary and tertiary industries was $0.23 \%, 2.57 \%$ and $1.29 \%$, respectively. It can be found that the comparative labor productivity of tertiary industry is higher than that of primary industry, but lower than that of secondary industry, showing basically the same pattern as in other western provinces. However, by horizontal comparison, Tibet lags behind in terms of the labor productivity of three industries among China's provinces and autonomous regions, and especially the labor productivity of secondary industry is in the penultimate position (Fig. 5), which demonstrates low technology content, low labor quality and low added value in Tibet's secondary industry. Through the comparative labor productivity analysis, it can be found that Tibet's secondary industry makes great strides and forms a relatively complete industrial system. Nevertheless, Tibet is still trailing far behind in secondary industry when compared with the less developed western regions or other regions of China; the secondary industry occupies a small share in the three industries, and fails to effectively stimulate Tibet's economy. Therefore, low output value, short industrial chain, low efficiency, and structural deviation of the entire industry, make it difficult to absorb the workforce. Focusing on the development of secondary industry, optimizing the industrial structure, and rationally adjusting the transfer of workforce to secondary industry, is still an important task for Tibet's industrial structure adjustment in the future. 


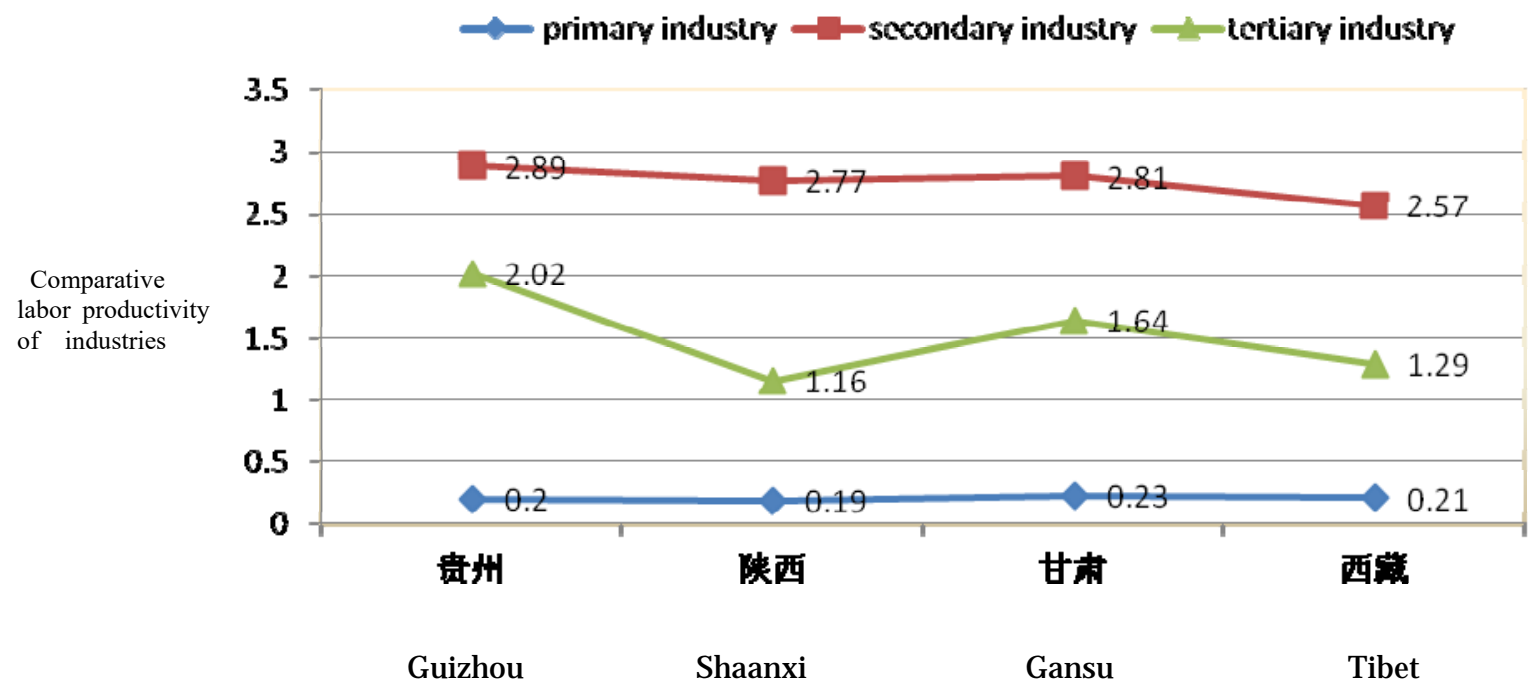

Fig. 5 Changes in comparative labor productivity of Tibet's three major industries

\subsection{Changes in industrial structure}

Tibet's industrial structure continues to change, from the original single farming and animal husbandry to the structure of "primary, tertiary and secondary industries". In 2013, it evolved into the industrial structure dominated by tertiary industry with plateau characteristics, the structural ratio of three major industries was adjusted to 9.9: 36.6: 53.5 (Fig. 6), and it formed the industrial structure of "tertiary, secondary and primary industries". In 2014, the ratio of employed persons was 43.7: 14.7: 41.6 in industrial development, and it formed the industrial structure of "primary, tertiary and secondary industries", which indicates that the industrial structure is still excessively dependent on farming and animal husbandry.

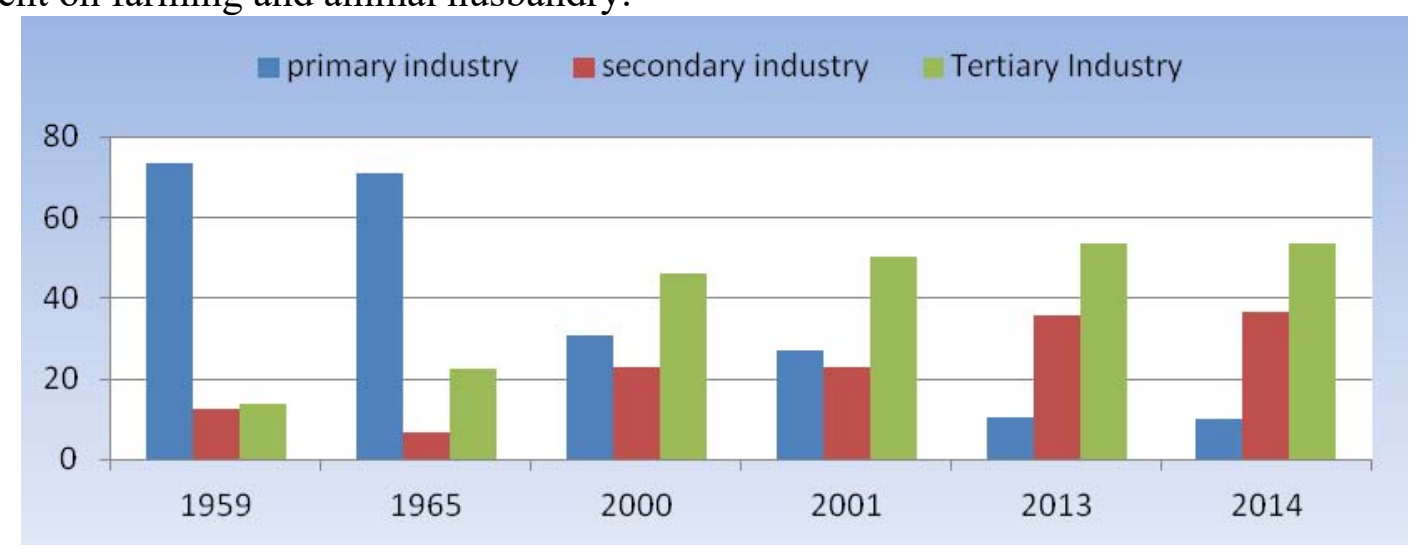

Fig. 6 Changes in Tibet's industrial structure

\section{Advantages for the development of Tibet's eco-industry}

\subsection{Resources}

Tibet is a region on the Tibetan Plateau, and it is the highest region on Earth. Tibet, often known as the "Third Pole of the Earth", has some of the world's tallest mountains, with several of them making the top ten list. Due to diverse topography and climate conditions, Tibet boasts an abundance of wildlife resources, and it is one of the areas with the most typical biodiversity in the world. Tibet has more than 9600 kinds of wild plants, and 6400 kinds of higher plants (including more than 5700 kinds of vascular plants and 700 kinds of bryophytes), belonging to more than 270 families and 1510 genera. Tibet has 855 unique species, and 300 kinds of Tibetan medicine for special medical purposes. 212 species of rare and endangered wild plants are listed in Appendix of Convention on International Trade in Endangered Species of Wild Fauna and Flora, Tibet has the most medium and large wildlife in China. It is China's most important area inhabited by rare and 
endangered wild animals, accounting for one third of endangered wildlife under state protection. There are 798 kinds of wild vertebrates, and 125 kinds of animals under state protection (including 45 kinds of animals under first-class state protection and 80 kinds of animals under second-class state protection). In addition, there are various kinds of special schizothoracine fish in Tibet, occupying over $90 \%$ of the world's schizothoracine fish; there are 488 kinds of birds, 22 of which are unique to Tibet; it has nearly 4000 kinds of insects. According to preliminary statistics, Tibet has more than 760 kinds of zooplankton in aquatic organisms, including 458 kinds of protozoa, 208 kinds of insects, and 56 kinds of branchiopod. There are a total of 340 kinds of diatoms in aquatic plants. Tibet is one of the five major forest areas in China, with living wood growing stock ranked second in China. It has 14.7156 million ha of forests and 2.288 billion $\mathrm{m} 3$ of forest growing stock ${ }^{[3]}$. By the end of 2014, the region had established 47 nature reserves ( 9 at national level, 14 at regional level, and 24 at county level), with total area of reserves reaching 0.4122 million $\mathrm{km} 2,34.35 \%$ of the region's land area. The region had established 22 ecological function conservation areas (one at national level) ${ }^{[4]}$. Tibet's rich ecological resources lay a solid foundation for the development of eco-industry.

\subsection{Development strategies}

During the "12th Five-Year Plan" period, the government of Tibet Autonomous Region introduced the strategy of developing the region in an ecological way, scientific development strategy and environmental security strategy, in order to form ecological security barrier, develop ecological economy and create an ecological Tibet. In 2009, the government developed Tibet's Ecological Security Barrier Protection and Construction Plan (2008-2030), and decided to implement three categories of ten ecological protection and construction projects. For more than six years, the state has invested a total of 7.8 billion yuan in these projects, and achieved significant ecological, social and economic benefits. Tibet has implemented some key projects in succession, such as project of afforestation in the watersheds of Brahmaputra River, Nujiang River, Lhasa River, Nyangqu River, Shiquan River and Nyang River, project about the conversion of degraded farmland into forest land, desertification prevention and control project, and construction project of Aimagang comprehensive ecological demonstration zone. Gradually, the plateau ecosystem stability is improved, the region's desertification area is reduced, and the sand control effect is obvious; returning grazing land to grassland helps to promote grassland restoration; the clean energy utilization is substantially improved in farming and pastoral areas; preservation of natural forest and ecological area wins initial success; ecosystem services are gradually improved, and ecological security barrier is well stabilized; ecosystem's role in water regulation is enhanced amid fluctuation, and water conservation is firmly maintained. The water conservation ability of Tibet's ecosystems of forest, grassland and wetland gradually decreases from southeast to northwest, and water conservation services have improved in fluctuation. In the sandy area of Brahmaputra River valley, the sand control project, characterized by planting grass and trees to fix sand, begins to form a certain scale, and ecosystem's wind prevention and sand fixation function is brought into play ${ }^{[5]}$. The eighth national forest inventory results show that Tibet is ranked first in China in terms of forest area, forest growing stock and non-commercial forest area. Tibet's Plan on Main Functional Area in 2014 proposed the national ecological security pattern based on the construction of "Three Barriers and Five Regions". On September 28, 2015, the Ministry of Science and Technology formally released 2014 National Sustainable Development Experimental Zone Acceptance List, and Nyingchi National Sustainable Development Experimental Zone became the first national sustainable development experimental zone in Tibet ${ }^{[6]}$. Tibet's ecological zone construction, national security strategy pattern and other strategies provide good policy support for the development of eco-industry.

\subsection{Eco-environment construction}

The Fifth Tibet Work Forum proposed that Tibet should be developed into an important national security barrier, an important ecological security barrier, an important strategic resource reserve base, an important agricultural base with plateau characteristics, an important cultural protection area with Chinese national characteristics, and an important tourist destination in the world. Since 
2000, the government of Tibet Autonomous Region has followed the order of nature, market rules and objective economic laws to take the road of industrial development with Tibetan characteristics, and has adopted environmentally friendly policies about eco-economic industry with characteristics. It places particular emphasis on protecting eco-environment in the development of special industries. The natural forest protection project is implemented in upper reaches of Yangtze River, to create 2200 ha of non-commercial ecological forests, and the forest ecological benefit compensation mechanism is employed to effectively manage and protect 10.1127 million ha of national key non-commercial forests in 7 cities and 65 counties of Tibet. In 2014, it launched the planning on ecological functional areas and set an ecological protection red line; carried out the environmental protection assessment in 74 counties of the region for the first time; allocated 3.955 billion yuan of ecological compensation funds, and increased the transfer payment scope in national key ecological function zones from 8 counties to 18 counties. Lhasa, Nyingchi, Shannan and Nagqu started to build national environmental protection model city, ecological Nyingchi, beautiful ecological demonstration zone and ecological grassland. Lhasa was rated as national environmental protection model city; Nyingchi and Shannan were approved as national demonstration area of ecological civilization. In 2014, there were a total of 2 counties, 16 townships and 204 administrative villages to be identified as ecological counties, ecological townships and ecological villages at regional level, respectively ${ }^{[7]}$. Tibet's eco-environment construction provides a good external environment for the development of eco-industry.

\subsection{Industrial park construction}

Tibet's industrial park started from scratch, and has developed by leaps and bounds. It promotes optimization of industrial structure and transformation of economic development model, and speeds up the construction of new industrialization and urbanization. Currently, various kinds of industrial parks, economic development zones and industrial clusters have flourished in Tibet, including Lhasa National Economic and Technological Development Zone, Dazi Industrial Park, Qushui Yajiang Industrial Park, Shannan Building Material Industrial Park, Nyingchi Biotechnology Industrial Park, and Nagqu Logistics Center. In 2015, Tibet's industrial parks achieved industrial output value of 7.11 billion yuan, a year-on-year growth of $42.1 \%$, and paid taxes of 7.143 billion yuan (all taxes of park), and Zangqing Industrial Park completed fixed asset investment of 3.566 billion yuan, achieved output value of more than 400 million yuan, and paid taxes of 97 million yuan ${ }^{[8]}$. Some industries with Tibetan characteristics and comparative advantages (such as deep processing of Tibet's farm and livestock products; plateau biological and green food (drink) manufacturing; research, development and production of Tibetan medicine; ethnic handicrafts; new building materials; optoelectronics industry), gradually start to cluster and develop in the industrial park. In the choice of project, the park strictly carries out the national and regional industrial policies, and prohibits energy-hungry, polluting and inefficient projects into the park. The green coverage rate of the park is not less than $40 \%$, and the park's management level and potential for development have been constantly enhanced. For example, Tibet's only state-level economic and technological development zone-Lhasa Economic and Technological Development Zone, has the afforestation rate of not less than 40\%; Dazi Industrial Park has formed the economic cycle system characterized by low input, high output, low consumption, high efficiency, low emission, and non-pollution in the development. The sound eco-environment construction and ecological technology adoption in the industrial park has boosted the development of Tibet's eco-industry.

\section{Constraints on the development of Tibet's eco-industry}

\subsection{Fragile eco-environment}

Tibet's plateau ecosystem is one of the most sensitive systems in China, and the extremely fragile eco-environment is subject to human damage. Due to low anti-interference ability, once the eco-environment is damaged, there will be a great impact and it is difficult to recover. Soil erosion, grassland degradation, desertification and other problems are getting increasingly serious; glaciers, snow-capped mountains and wetlands are dwindling year by year; mudslides, landslides, snowstorms and other natural disasters have sometimes occurred, posing a threat to biodiversity. 
Fragile eco-environment makes industrialization and urbanization progress in a very limited land space. The special geographical environment makes it difficult to resolve these problems, so it is necessary to protect and restore the environment, in order to promote the development of Tibet's eco-industry.

\subsection{Unsound infrastructure}

Tibet's industry soars from the ruins of the feudal serfdom and extremely backward natural economy, neither having the groundwork of modern civilization, nor relying on the natural environment as well as that in the mainland. At the same time, Tibet has low level of industrial economic development, industrial development started relatively late, and insufficient infrastructure input has constrained the investment in Tibet's industry. Consequently, it causes the development and structural optimization of Tibet's industry to lag behind in China.

\subsection{Backward ecological economy and technology}

In view of the contradiction between Tibet's fragile eco-environment construction and great-leap-forward economic development, there is a need to vigorously promote various types of eco-technology. However, there is still a shortage of studies on technical measures suitable for the plateau industrial development in the current practice of eco-industry, and some issues, concerning traditional technological development, high-tech introduction and the like, come into focus now. Especially for Tibet's industry, the technology content is not high in the leading industry, some energy-hungry and polluting traditional industries are still dominant, and the high-tech industry has enormous room for upgrading and ecologicalization; some companies still adopt a kind of linear industrial model with high consumption and high pollution, the extensive management results in low efficiency of resource and energy use, and industrial growth is too dependent on energy consumption, leading to serious pollution.

\subsection{Low level of economic development}

Economic development is the most fundamental factor to promote the development of eco-industry, and Tibet's eco-industry makes steady progress with economic boom. Tibet's GDP increased from 4.599 billion yuan in 1994 to 80.767 billion yuan in 2013, showing an upward trend every year. Fast-growing economy is a necessary condition for the development of eco-industry, and industrial technology advance has played a significant role in promoting the development of eco-industry. Only when the economic aggregate is increasing and economy is growing fast can eco-industry be better developed.

\section{Choice of development models for Tibet's eco-industry}

According to the change in Tibet's eco-industry and the problems in Tibet's industrial development, the development models for Tibet's eco-industry should be centered around ecological design, stress social, economic and ecological benefits, and strive to achieve coordinated development of ecological and economic systems. Based on the goal of eco-industry, this article brings forward three economic development models (eco-agriculture with plateau characteristics; industrial symbiosis in eco-industrial park; community participation-based ecotourism) for the development of Tibet's eco-industry, with ecological education and ecological management as protection mechanism (Fig. 7), in order to enable industry and eco-environment to achieve coordinated and sustainable development, and finally realize eco-industry sustainability. 


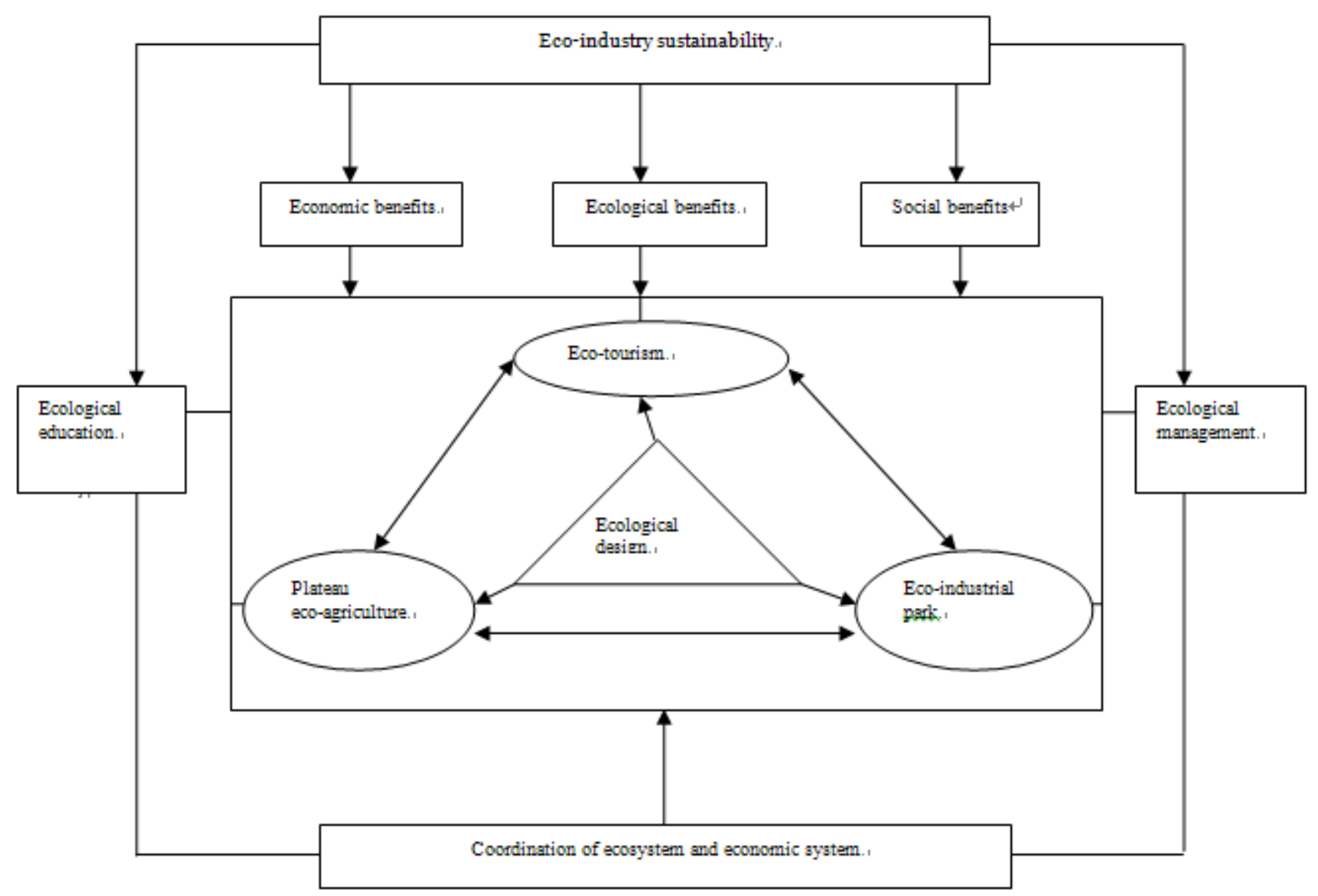

Fig. 7 Development models for Tibet's eco-industry

\subsection{Eco-agriculture with plateau characteristics}

Developing eco-agriculture with plateau characteristics. According to the principles of ecological economy and characteristic eco-industry, we can use the eco-technologies and eco-management techniques suitable for the plateau agricultural development, to build the modern eco-agriculture demonstration zones with plateau characteristics, and take full advantage of the unique plateau ecological resources, to actively develop characteristic farming and animal husbandry and the plateau biological industry, and bring out pollution-free and organic agricultural products. It is necessary to highlight "specialization, standardization, informatization and modernization", and make great efforts to improve infrastructure conditions in ecological resources-rich regions for the development of distinctive eco-agriculture.

Developing the eco-agriculture-based circular economy with plateau characteristics and actively cultivating the leading plateau agricultural enterprises. Based on the carrying capacity of agricultural resources, environmental capacity, ecological types and socio-economic development, we must implement the strategic plan of ecological civilization construction, strictly control total water consumption for agriculture, reduce the application of chemical fertilizers and pesticides, recycle and reuse manure, straw and plastic sheeting for farm use, in order to achieve sustainable development of agriculture and improve the utilization rate of agricultural resources. Meanwhile, we can make enterprises stronger and industry more competitive by increasing the added value, extending the industrial chain, and achieving the development goals of "industrial development, intensive management, large-scale farming and breeding, specialized production and integrated services".

Developing "blue economy" model. We can combine the traditional Chinese culture with eco-agriculture to adopt the "blue economy" model developed by Gunter Pauli who is committed to the promotion of non-waste, non-pollution and low-cost ways to tackle issues that cause environmental and related problems, and pursue sustainable development of human society and natural ecology. Specifically, we can use "learning from nature" in China's agricultural culture to 
build an ecological supply chain of agriculture, thereby achieving waste-free, pollution-free and low-cost agricultural development goals. Taking into account the characteristics of Qinghai-Tibet Plateau, we can adopt the complex farming - forestry - animal husbandry eco-efficient model, grain feed - pig_biogas - manure model, forest - fruit-animal husbandry model, farming — animal husbandry model, and other efficient three-dimensional network type eco-agriculture models.

Developing intelligent eco-agriculture. We can use modern information technology and Internet technology to develop "Internet+ agriculture" and "Internet+ modern farm machine" to promote the development of intelligent plateau eco-agriculture. Tibet's ecotourism, agritourism and plateau eco-agriculture can be combined to develop intelligent eco-agriculture, extend industrial chain, achieve industrial integration and increase benefits.

\subsection{Industrial symbiosis in eco-industrial park}

There are two kinds of industrial symbiosis models - autonomous entity symbiosis model and compound entity symbiosis model, represented by Denmark's Kalundborg Eco-industrial Park and China's Guitang Group Eco-industrial Park. The two models are most widely used in the current symbiotic union of eco-industrial park ${ }^{[9]}$. Tibet's industrial park is developed in the form of eco-industrial park, with eco-industrial chain as carrier ${ }^{[10]}$. The flow and storage of material, energy and information in eco-industrial system are similar to that in natural ecosystem, and all the elements are interdependent and interactive to form a complex interconnected network system. By establishing the logistics, energy flow and information flow link between enterprises, the eco-industrial chain achieves the operating mode of natural ecosystem. In this operating mode, we can use advanced technology, energy-saving and environmentally-friendly technology to develop the emerging industries with plateau characteristics and form a new economic growth point. Based on the principles of "reduction, reuse and recycling", it is necessary to actively explore and promote the circular economic development model in the areas of industry, agriculture and service sector; build resource recycling system and green consumption system to promote the development of circular economy; increase support to cleaner production technologies and projects, establish cleaner production information system, and speed up the construction of cleaner production technology service system.

The industrial park should also gradually expand symbiotic chain network, and make the existing industries closely related in a symbiotic network, to achieve horizontal and vertical linkage of industries. In the areas with rich distinctive agricultural resources, there is a need to encourage the development of food processing, bio-pharmaceutical industry and other related industries, and strengthen scientific design and technology innovation to form a virtuous circle of agriculture and processing industry. In the areas rich in mineral resources, we must actively guide township enterprises to gather in the industrial park, and actively build an industrial symbiosis network system.

\subsection{Community participation-based ecotourism}

There is a natural link between tourism industry and eco-industry. Tourism industry is an environment-based industry while eco-industry can provide the necessary material basis for the development of tourism industry. The two industries interact with each other, and it is difficult to maintain the coordinated development of tourism industry and eco-industry ${ }^{[11]}$. Ecotourism model is a case in point.

Community participation-based ecotourism is a development model simultaneously led by government and businesses. In this model, the community residents are the main force of tourism development, while the community elites play an important role in tourism development.

Community participation-based ecological development model is common in the areas relying on settlement for tourism development. In Tibet, tourist towns and characteristic tourist villages, as an integral part of tourism industry, play a crucial role in local economic and social development. The community participation-based tourist destinations usually take settlements as core resources, including landscape, industry and residents in settlements, involving the areas of ecology, production and living. For example, rural tourism takes agriculture, rural areas and farmers as the core resources. The community residents, who provide accommodation, catering and entertainment 
services for tourists using their own gardens, houses and labor, gradually become the major force of tourism supply. The community participation-based ecotourism development model takes shape by degrees, and it is an important manifestation of Tibet's characteristic tourism development road. Conspicuously, this model has an important part to play in promoting tourism resource development, providing basic tourism services, increasing community residents' income, improving the overall quality, perfecting infrastructure and ameliorating living environment.

With constantly changing tourism needs and increasingly market competition, the community participation-based ecotourism model must be geared to breakthroughs in development vitality, growth potential, institutional innovation force, product competitiveness, and industrial support force. At present, the community participation-based ecotourism should be combined with the implementation of villagers' self-governance law to promote democratic election, democratic decision making, democratic management and democratic supervision, and constantly improve the quality of community governance. At the same time, it is necessary to strengthen community capacity building, improve the strategic management, innovation ability and executive capability of community leaders, and use the means of training and investigation trip to enhance the service and management capacity of community residents, and establish cultural awareness and innovation consciousness; foster professional cooperatives, establish joint-stock tourism enterprises, improve the distribution of benefits, and use modern enterprise system for management; use the forms of think tank, outsourcing or joint venture to introduce external resources, and some agencies and personnel about tourism planning, product planning, marketing, brand building, capital operation and legal advice, as well as a number of businesses with great economic strength, cultural vision and strategic vision, to build a community-led development model operated by businesses and supported by society.

\section{Conclusion}

With the dramatic economic development in Tibet, the carrying capacity of natural resources and eco-environment becomes the main factor restricting economic growth. Development of eco-industry is one of the effective ways to achieve coordinated and sustainable development of industrial economy and eco-environment. On the basis of industrial analysis, eco-industry and labor productivity comparison, and eco-environment coordination analysis, this article performs studies on the factors that affect the development of eco-industry in Tibet, including fragile eco-environment, unsound infrastructure, backward ecological economy and technology, and low level of economic development. This article puts forth three economic development models for the eco-industry with Tibet characteristics: eco-agriculture with plateau characteristics; industrial symbiosis in eco-industrial park; community participation-based ecotourism.

\section{Acknowledgement}

Supported by National Natural Science Foundation (71263048); Project of Tibet Autonomous Region Department of Education (2013ZJRW14, 2013ZJJG11).

\section{References}

[1] FAN HY, ZHANG YQ. Reflection on the development of eco-industry in Heilongjiang Province [J]. Heilongjiang Social Sciences, 2005, 02: 35-37. (in Chinese).

[2] CHEN CM. Current situation of development and measures about eco-industry in Fujian Province [J]. Journal of Minnan Normal University (Philosophy and Social Sciences), 2015,03: 80-86. (in Chinese).

[3] Tibet ranked first in China in terms of the number of large and medium-sized wild animals [N]. Tibet Business Daily, 2015-6-9. (in Chinese). 
[4] Environmental bulletin of Tibet Autonomous Region in 2014. [N]. Tibet Daily, 2015-06-08. (in Chinese).

[5] Remarkable achievements in Tibet's ecological security barrier protection and construction. http://news.youth.cn/jsxw/201508/t20150827_7055240.htm, 2015-08-27. (in Chinese).

[6] Tibet's first national experimental zone for sustainable development-Nyingchi experimental zone to be established. http://www.chinatibetnews.com/xw/xzyw/201605/t20160512_1225619.html, 2016-05-12. (in Chinese).

[7] Environmental bulletin of Tibet Autonomous Region in 2014. [N]. Tibet Daily, 2015-06-08. (in Chinese).

[8] Pema Dolma. Industrial output growth of over 40\% in Tibet's various industrial parks last year. http://www.chinanews.com/df/2016/02-15/7758004.shtml, 2016-02-15. (in Chinese).

[9] WANG ZH, WU CY, WANG GH. Comparative study of two industrial symbiosis models in eco-industrial park [J]. Soft Science, 2002, 02: 11-14+18. (in Chinese).

[10] WANG X, ZHANG HQ. Practice and development trend of China's eco-economic industry [J]. Environmental Protection and Recycling Economy, 2009, 12: 71-73. (in Chinese).

[11] LI ZL. Coordination analysis of eco-industry and tourism industry from coupling perspective - based on the 2005-2014 data in Hunan Province [J]. Journal of Hunan Finance and Economics University, 2015, 06: 105-111. (in Chinese). 